\title{
Implicações do uso e ocupação do solo para o planejamento e gestão ambiental da Bacia Hidrográfica do Rio Aquidauana, Mato Grosso do Sul
}

\author{
Implications of land use and occupation for environmental planning and \\ management of the Aquidauana River Basin, Mato Grosso do Sul

\begin{abstract}
Implications d'utilisation et occupation du sol pour la planification et gestion
\end{abstract} \\ environment dans le Bassin Versant du Rivière Aquidauana, Mato Grosso do Sul
}

\author{
Implicaciones del uso y ocupación del suelo para la planificación y gestión \\ ambiental de la Cuenca del Rio Aquidauana, Mato Grosso do Sul
}

\author{
Paulo Roberto Joia ${ }^{1}$ \\ Vicentina Socorro da Anunciação ${ }^{1}$ \\ Alfredo Aguirre da Paixão ${ }^{1}$
}

Recebido em 21/12/2016; revisado e aprovado em 03/07/2017; aceito em 23/08/2017

DOI: http://dx.doi.org/10.20435/inter.v19i2.1404

\begin{abstract}
Resumo: As bacias hidrográficas são as unidades espaciais de gestão e planejamento dos recursos hídricos. As informações sobre o número de habitantes e a área das bacias contribuem para a interação entre a administração pública e a população a ser servida pelo recurso natural. Este trabalho tem como objetivo levantar subsídios para a gestão da bacia hidrográfica do rio Aquidauana, estimando o seu número de habitantes e a sua área. Foram identificados dois órgãos de gestão atuantes na bacia do rio Aquidauana: o CIDEMA e o CBH Rio Miranda. Constatou-se que os cinco municípios mais relevantes da bacia, em relação à população e área, participam dos órgãos de gestão da bacia, podendo ser um facilitador nas tomadas de decisões. Conclui-se que, devido à baixa densidade demográfica da bacia, há uma baixa pressão sobre os recursos a serem utilizados.
\end{abstract}

Palavras-chave: bacia hidrográfica; planejamento e gestão; recursos hídricos.

Abstract: The hydrographic basins are the spatial units for planning and management of the water resources. Information on the number of inhabitants and the area of the basins contribute to the interaction between the government and the population to be served by natural resource. This work aims to raise subsidies for the management of the hydrographic basin of the river Aquidauana, estimating the number of its inhabitants and its area. Two active management entities have been identified in the Aquidauana river basin: the CIDEMA and $\mathrm{CBH}$ Rio Miranda. It was found that the five most important cities of the drainage basin in relation to population and area, part of basin management bodies, may be a facilitator in decision making. It was concluded that due to the low population density of the basin there is a low pressure on resources to be used.

Keywords: river basin; planning and management; water resources.

Résumé: Les bassins versants sont les unités spatiales de la gestion et de la planification des ressources en eau. Information sur le nombre d'habitants et la zone des bassins contribuent à l'interaction entre le gouvernement et la population d'être servis par des ressources naturelles. Ce travail vise à augmenter les subventions pour la gestion du bassin du rivière Aquidauana, l'estimation du nombre de ses habitants et sa superficie. Deux entités de gestion active ont été identifiés dans le bassin de la rivière Aquidauana: le CIDEMA et CBH Rio Miranda. II a été constaté que les cinq comté les plus importantes du bassin par rapport à la population et la surface, participent des organes de gestion du bassin, peut être un facilitateur dans la prise de décision. II a été conclu qu'en raison de la faible densité de population du bassin il y a une faible pression sur des ressources à utiliser.

Mots-clés: bassin versant; planification et gestion; ressources en eau.

Resumen: Las cuencas son las unidades espaciales de gestión y planificación de los recursos hídricos. La información sobre el número de habitantes y el área de las cuencas contribuyen a la interacción entre el gobierno y la población a ser atendida por este recurso natural. Este trabajo tiene como objetivo recopilar información para la gestión de la cuenca del río Aquidauana, haciendo una estimatión del número de sus habitantes y su área. Dos entidades activas de gestión han sido identificados en la cuenca del río Aquidauana:

\footnotetext{
${ }^{1}$ Universidade Federal de Mato Grosso do Sul (UFMS), Aquidauana, Mato Grosso do Sul, Brasil.
} 
la CIDEMA y CBH Río Miranda. Se encontró que los cinco municipios más importantes de la cuenca en relación a población y superficie, participan de los órganos de gestión de cuenca, pudiendo ser un facilitador en la tomada de decisiones. Se concluyó que debido a la baja densidad de población de la cuenca hay una presión baja en los recursos para ser utilizado.

Palabras clave: cuenca hidrográfica; planificación y gestión; recursos hídricos.

\section{INTRODUÇÃO}

Atualmente, a gestão de bacias hidrográficas mostra-se como desafio para os governantes em gerenciar as inúmeras finalidades propostas para essas áreas, assim surgem organismos que auxiliam no gerenciamento dos recursos hídricos como o Conselho Nacional de Recursos Hídricos (CNRH), ocupando a mais alta instância na hierarquia no Sistema Nacional de Gerenciamento de Recursos Hídricos, considerado um colegiado de mediação entre os diferentes usuários d'água.

Segundo o CNRH (s.d.), entre as suas competências estão a de analisar propostas de alteração da legislação pertinente aos recursos hídricos, arbitrar conflitos sobre recursos hídricos, aprovar propostas de instituição de comitês de bacia hidrográfica, os Comitês de Bacias Hidrográficas (CBH's).

Aos CBH's atribuem-se as competências de aprovar o plano de recursos hídricos da bacia, de arbitrar conflitos pelo uso da água e de sugerir os valores da cobrança pelo uso da água (CBH, s.d.). Essas competências destacam a importância dos comitês para a gestão dos recursos hídricos das bacias hidrográficas.

Quanto aos consórcios intermunicipais de bacias hidrográficas, segundo o CNRH (s.d.), o estado de Mato Grosso do Sul possui dois dos 37 consórcios brasileiros. Em Mato Grosso do Sul, foram constituídos o Consórcio Intermunicipal para Desenvolvimento Integrado dos Rios Miranda e Apa (CIDEMA) e o Consórcio Intermunicipal para Desenvolvimento Sustentável da Bacia do Rio Taquari (COINTA).

A bacia do rio Aquidauana faz parte da bacia hidrográfica do rio Miranda (Figura 1), que, por sua vez, é afluente do rio Paraguai. Muitos municípios localizados na bacia fazem parte do CIDEMA. 


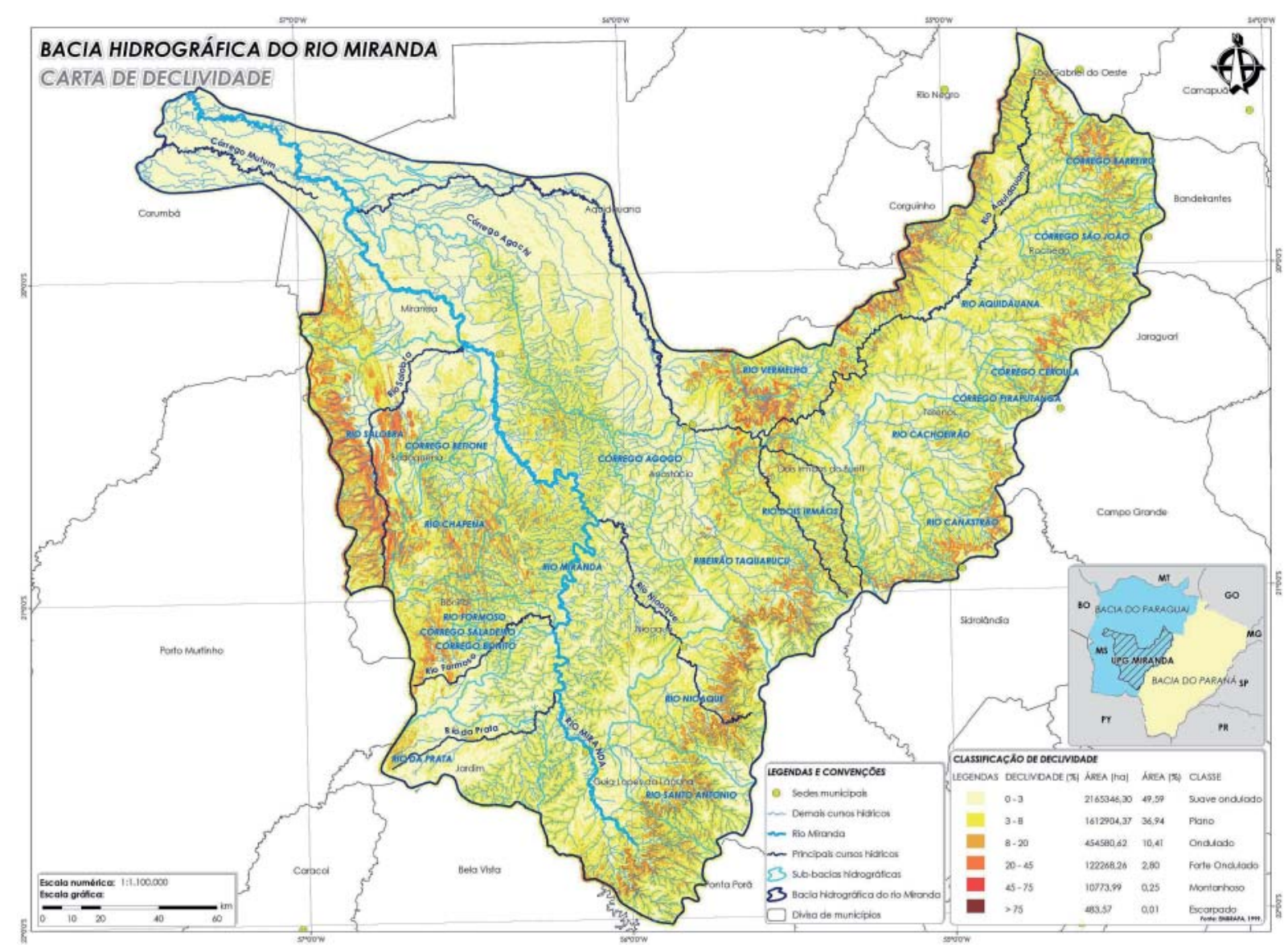

Figura 1 - Bacia hidrográfica do rio Miranda e Aquidauana

Fonte: Secretaria de Estado de Meio Ambiente, do Planejamento e da Ciência e Tecnologia/Instituto de Meio Ambiente de Mato Grosso do Sul (SEMAC/IMASUL, 2013, p. 40).

Quanto à compartimentação geomorfológica, a bacia do rio Aquidauana atravessa áreas de planície (planície Pantaneira) e áreas de planalto (serra de Maracaju) (SECRETARIA DE PLANEJAMENTO E COORDENAÇÃO GERAL [SEPLAN-MS], 1990). O baixo e parte do médio curso do rio estão inseridos no Pantanal Sul-mato-grossense, enquanto que o alto e a outra parte do médio curso pertencem ao domínio do Cerrado. Desse modo, a bacia envolve uma área de grande biodiversidade e sociodiversidade.

O rio Aquidauana abastece a população urbana de vários municípios, além de ser utilizado para a pesca, o turismo e o consumo da pecuária, que é a principal atividade econômica dos municípios da bacia.

O rio Aquidauana nasce na serra de Maracaju, na região norte do estado de Mato Grosso do Sul, e deságua no rio Miranda, na região do Pantanal, percorrendo uma extensão de $620 \mathrm{~km}$ (SEMAC-MS, 2011). A hipsometria do canal principal apresenta variação entre $764 \mathrm{~m}$ a $85 \mathrm{~m}$ de altitude. O rio Aquidauana possui afluentes pouco expressivos em extensão, sendo os principais o ribeirão Taquaruçu, o rio Dois Irmãos e o rio Cachoeirão, todos afluentes da margem esquerda.

As atividades econômicas desenvolvidas refletem diretamente na organização do espaço geográfico e na dinâmica socioambiental das populações inseridas na bacia hidrográfica do rio Aquidauana. A partir da interação entre a sociedade e a natureza, importantes políticas relacionadas aos recursos hídricos poderão ser traçadas pelas lideranças locais, sendo que o ordenamento físico-territorial da bacia é um importante subsídio para tais políticas. 
Este trabalho tem por objetivo levantar subsídios para o planejamento e a gestão da bacia hidrográfica do rio Aquidauana, estimando o seu número de habitantes, a sua área e os reflexos socioambientais no espaço geográfico em questão.

\section{METODOLOGIA}

Os procedimentos iniciais para a realização deste trabalho consistiram na utilização de uma base cartográfica, elaborada por Silva (2013), da qual foi delimitada a área da bacia hidrográfica por município. A partir disso, calculou-se a área por setor de recenseamento municipal, de acordo com divisão feita pelo Instituto Brasileiro de Geografia e Estatística (IBGE, 2010), e a área total da bacia.

Os dados referentes à população da bacia hidrográfica foram obtidos através do cálculo estimado por setor de recenseamento, em nível municipal, extraídos da sinopse do censo demográfico do IBGE para 2010.

A partir das informações de área e população, calculou-se a densidade demográfica por setor de recenseamento municipal.

Para confecção do mapa da organização espacial, que teve como fonte o Mapa Multimodal Mato Grosso do Sul 2013 (DEPARTAMENTO NACIONAL DE INFRA-ESTRUTURA DE TRANSPORTES [DNIT], 2013), foram utilizadas informações da localização e da área dos assentamentos rurais e terras indígenas, extraídas do PA INCRA 2005 e Terras Indígenas MS FUNAI 2008, disponíveis no IMASUL (s.d.) e das prefeituras municipais, através de contato feito em 2014. Também através de informações das prefeituras municipais, produziu-se um quadro da situação do saneamento básico, por município, inserido na bacia hidrográfica do rio Aquidauana.

Os resultados foram confrontados com os documentos do Comitê de Bacia Hidrográfica do Rio Miranda e do CIDEMA.

\section{PLANEJAMENTO E GESTÃO DE BACIA HIDROGRÁFICA}

Para Christofoletti (1980), as bacias hidrográficas são compostas por um conjunto de canais de escoamento de água, sendo uma unidade física limitada pelos divisores de água. Também compreendida como rede hidrográfica, ela é uma unidade natural que recebe a influência da região que drena, é um receptor de todas as interferências naturais e antrópicas que ocorrem na sua área tais como: topografia, vegetação, clima e uso e ocupação.

Considerando que as bacias hidrográficas possuem uma compartimentação topográfica, iniciando com as cotas mais altas e terminando nas mais baixas, qualquer alteração no ambiente a montante do ponto de análise implica alterações nas áreas a jusante.

A bacia hidrográfica compõe uma unidade de análise ambiental, adequada para fins de planejamento e gestão, visto que se caracterizam como uma unidade física bem definida no que diz respeito às relações estabelecidas entre os elementos constituintes (PORTO; PORTO, 2008).

Para o planejamento territorial, qualquer unidade de área insere-se em uma bacia hidrográfica, por isso ela possui ampla abrangência espacial.

Uma abordagem de gerenciamento, pesquisa e elaboração de banco de dados a partir da bacia hidrográfica deve incluir uma valorização dos "serviços" dos ecossistemas aquáticos e dos recursos hídricos, uma capacidade preditiva baseada em um programa denso e tecnicamente avançado de monitoramento, em um sistema adequado de governança de água 
com a finalidade de promover oportunidades de desenvolvimento regional e sustentável a partir da água disponível e da demanda. (TUNDISI, 2008).

A caracterização geográfica da bacia hidrográfica pode ser elaborada de acordo com os aspectos fitogeográficos e socioeconômicos até se chegar a um zoneamento ambiental (MENDONÇA, 1999). A conjugação de diversos elementos naturais e sociais permite a delimitação de várias regiões geográficas nas áreas das bacias hidrográficas.

Segundo Porto e Porto (2008), para uma gestão sustentável dos recursos hídricos no contexto de bacias hidrográficas, há necessidade de aplicação de um conjunto mínimo de instrumentos de gestão, a saber: uma base de dados e informações socialmente acessível, a definição clara dos direitos de uso, o controle dos impactos sobre os sistemas hídricos e o processo de tomada de decisão.

Para Borsoi e Torres (1997), a primeira experiência brasileira na gestão de recursos hídricos teve início na década de 1930 e estava vinculada à questão agrícola: em 1933, foi criada a Diretoria de Águas, depois Serviço de Águas, no Ministério da Agricultura.

Em 1997, é instituída a Política Nacional de Recursos Hídricos (BRASI, 1997), que incentiva a descentralização da gestão dos recursos hídricos para os comitês de bacia hidrográfica, para prevenir e mediar os conflitos provocados pelo uso da água, os quais cada vez mais vão se evidenciando no território nacional, justificados pelo crescimento populacional e econômico.

Em Mato Grosso do Sul, os conflitos existentes pelo uso d'água são basicamente relacionados aos conflitos socioambientais, típicos de uma região brasileira com a economia embasada na agropecuária, cujos problemas são originários do crescimento da população, uso inadequado do solo, desigualdades sociais, diferentes padrões de consumo, impactos oriundos da contaminação das águas, incremento crescente das atividades econômicas e da pouca governabilidade hídrica. Essa realidade justifica a necessidade de um planejamento para o desenvolvimento da região, articulando entre as instâncias governamentais (federal, estadual, municipal), usuários de água e sociedade para evitar o agravamento das possibilidades de conflitos de uso e prejuízos à qualidade e à disponibilidade das águas. (BROCH, 2013).

Yassuda (1993) salienta uma das contradições no planejamento das bacias hidrográficas em que a prosperidade das cidades causa a decadência dos recursos ambientais, a começar pela destruição de valores fundamentais da água em benefício da otimização de setores de produção.

A bacia hidrográfica necessita de gerenciamento e planejamento porque é a unidade territorial onde as relações entre o meio natural e os componentes antrópicos se manifestam, além de envolver um dos principais elementos de discussão atual, a água.

Na gestão dos recursos hídricos, procura-se estabelecer a melhor forma de utilização, reduzindo o consumo desnecessário nos seus diferentes campos, como no caso da irrigação, indústria, alimentação, turismo e a própria descedentação de pessoas e animais. Os organismos institucionais que podem gerir essas demandas de água são os comitês de bacias hidrográficas e consórcios intermunicipais.

Para Marinho e Moretti (2013), nas políticas públicas de conservação ambiental, a criação dos comitês de bacias hidrográficas pode expressar territorialidades associadas às representações e instâncias de poder de controle de usos e apropriação das águas.

No que se refere ao planejamento e gestão de bacias hidrográficas, devido às disjunções político-administrativas e físico-territoriais, os conflitos recaem sobre a área territorial adotada para o planejamento, uma vez que os limites físico-territoriais da bacia hidrográfica não coincidem 
com os limites político-administrativos municipais, dificultando a congruência de interesses múltiplos.

Os comitês de bacias hidrográficas fariam esse papel intermediador de conflitos. Os municípios possuem competência para realizar o ordenamento e a ocupação do solo dentro de seu território. Para Porto e Porto (2008), gerenciar o território, utilizando-se da bacia hidrográfica como unidade de planejamento, significa uma evolução no modelo de gestão pública sem, contudo, romper com o modelo federativo.

\section{A BACIA HIDROGRÁFICA DO RIO AQUIDAUANA: ÁREA E POPULAÇÃO}

A bacia hidrográfica do rio Aquidauana é uma sub-bacia do rio Miranda que, por sua vez, é afluente do rio Paraguai. A bacia está localizada na porção norte-centro-oeste do estado de Mato Grosso do Sul, estendendo-se da Serra de Maracaju, no município de São Gabriel do Oeste, até a planície Pantaneira na confluência com o rio Miranda, o município de Aquidauana. A área da bacia está localizada entre os paralelos 19 19' 01" e 210 13'49" de latitude sul e os meridianos 560 49' 11" e 54ㅇ 16' 44" de longitude oeste.

A área da bacia hidrográfica do rio Aquidauana abrange parte de 16 municípios do estado de Mato Grosso do Sul, são eles: Anastácio, Aquidauana, Bandeirantes, Camapuã, Campo Grande, Corguinho, Dois Irmãos do Buriti, Jaraguari, Maracaju, Miranda, Nioaque, Rio Negro, Rochedo, São Gabriel do Oeste, Sidrolândia e Terenos (Figura 2).

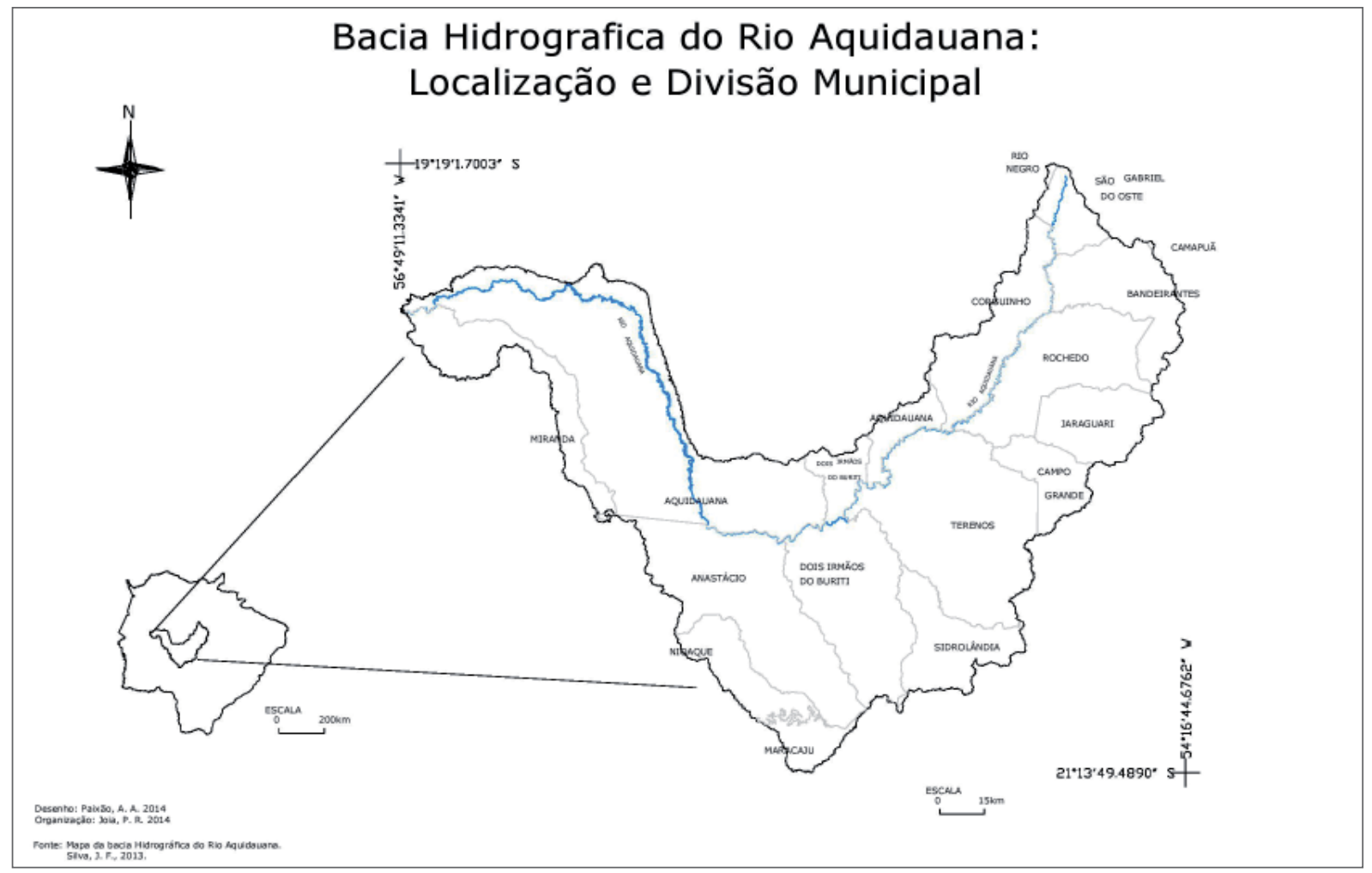

Figura 2 - Bacia Hidrográfica do rio Aquidauana: localização e divisão municipal. Fonte: SILVA, 2013

A área estimada para a bacia hidrográfica do rio Aquidauana é de 21.369 km² (Tabela 1). Entre os municípios inseridos na bacia, os que possuem em termos absolutos uma maior extensão 
territorial são: Aquidauana $\left(5.034 \mathrm{~km}^{2}\right)$, Terenos $\left(2.826 \mathrm{~km}^{2}\right)$, Anastácio $\left(2.386 \mathrm{~km}^{2}\right)$ e Dois Irmãos do Buriti $\left(2.220 \mathrm{~km}^{2}\right)$, respectivamente. Entretanto os municípios que estão relativamente mais inseridos na área da bacia hidrográfica são os de Rochedo (100,00\%), Terenos (99,44\%), Dois Irmãos do Buriti $(94,72 \%)$ e Anastácio (80,94\%), respectivamente.

Tabela 1 - Municípios pertencentes à bacia hidrográfica do rio Aquidauana: área absoluta e relativa

\begin{tabular}{|c|c|c|c|c|}
\hline Município & $\begin{array}{r}\text { Área Total } \\
\left(\mathrm{km}^{2}\right)^{1} \\
\end{array}$ & $\begin{array}{r}\text { Área na bacia } \\
\left(\mathrm{km}^{2}\right)\end{array}$ & $\begin{array}{r}\text { Porcentagem sobre a área } \\
\text { total do município (\%) }\end{array}$ & $\begin{array}{l}\text { Porcentagem sobre a } \\
\text { área total da bacia (\%) }\end{array}$ \\
\hline Anastácio & $2.947,743$ & $2.386,139$ & 80,94 & 11,16 \\
\hline Aquidauana & $16.951,645$ & $5.034,765$ & 29,70 & 23,55 \\
\hline Bandeirantes & $3.119,139$ & $1.156,295$ & 37,07 & 5,40 \\
\hline Camapuã & $6.241,736$ & 2,713 & 0,04 & 0,01 \\
\hline Campo Grande & $8.106,159$ & 585,054 & 7,21 & 2,73 \\
\hline Corguinho & $2.641,840$ & $1.191,571$ & 45,10 & 5,57 \\
\hline Dois Irmãos do Buriti & $2.344,002$ & $2.220,358$ & 94,72 & 0,38 \\
\hline Jaraguari & $2.915,907$ & 876,253 & 30,05 & 4,09 \\
\hline Maracaju & $5.297,358$ & 341,372 & 6,44 & 1,59 \\
\hline Miranda & $5.475,525$ & $1.105,111$ & 20,18 & 5,17 \\
\hline Nioaque & $3.922,904$ & 682,868 & 17,40 & 3,19 \\
\hline Rio Negro & $1.808,163$ & 15,903 & 0,87 & 3,19 \\
\hline Rochedo & $1.561,356$ & $1.561,356$ & 100,00 & 7,30 \\
\hline São Gabriel do Oeste & $3.867,771$ & 415,537 & 10,74 & 1,94 \\
\hline Sidrolândia & $5.289,343$ & 967,164 & 18,28 & 4,52 \\
\hline Terenos & $2.842,295$ & $2.826,629$ & 99,44 & 13,22 \\
\hline Total & $75.332,892$ & $21.369,095$ & - & 99,97 \\
\hline
\end{tabular}

Fonte: ${ }^{1}$ IBGE (2010)

De acordo com os dados levantados, pode-se deduzir que os municípios mais representativos da bacia hidrográfica do rio Aquidauana são os de Aquidauana, Anastácio, Dois Irmãos do Buriti, Terenos e Rochedo, ou seja, cinco municípios dentre os dezesseis que estão inseridos na bacia.

Por outro lado, os municípios que possuem suas sedes na área da bacia são os de: Anastácio, com a população da sede de 19.674 habitantes; Aquidauana, com a população da sede de 35.926 habitantes; Corguinho com 1.872 habitantes; Dois Irmãos do Buriti, com 4.705 habitantes; Jaraguari, com 1.786 habitantes; Rochedo, com 2.889 habitantes; Sidrolândia, com 27.783 habitantes; e Terenos, com 7.275 habitantes (IBGE, 2010). Vale ressaltar que Sidrolândia e Jaraguari possuem parte da sede municipal pertencente a outras bacias hidrográficas.

A densidade demográfica na bacia do rio Aquidauana somente atinge a sua maior concentração (acima de 100 habitantes/ $\mathrm{km}^{2}$ ) nas sedes dos municípios e seus distritos; em sua maior extensão, a densidade demográfica não ultrapassa o valor de até 5 habitantes por quilômetro quadrado (Figura 3). Para a média Brasileira, que era de 22,4 hab/ $\mathrm{km}^{2}$, em 2010, a densidade demográfica com valores inferiores a $5 \mathrm{hab} / \mathrm{km}^{2}$ é considerada baixa, uma área subpovoada. 


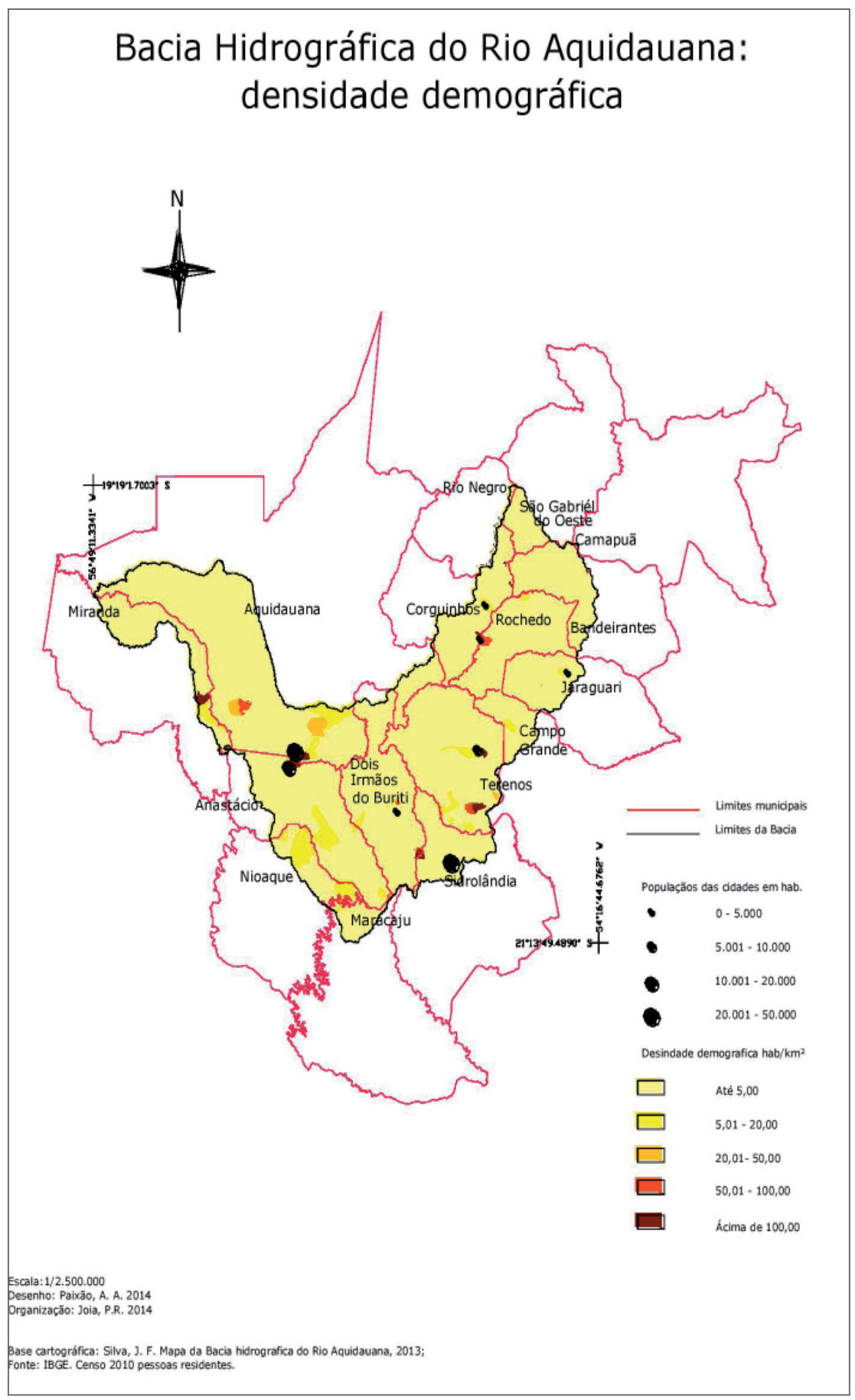

Figura 3 - Bacia hidrográfica do rio Aquidauana, densidade demográfica

Fonte: IBGE, 2010.

A população estimada para a bacia do rio Aquidauana, em 2010, era de 125.192 habitantes (Tabela 2). Entre os municípios inseridos na bacia, os que possuíam em termos absolutos um maior número de habitantes eram: Aquidauana, com 44.491 habitantes (dos quais 97.53\% estavam inseridos na área da bacia); Anastácio, com 23.566 habitantes; e Terenos, com 17.120 habitantes. Entretanto, dentre os municípios inseridos na bacia, os que possuíam o maior número de população relativa eram: Rochedo (100,00\%), Terenos $(99,84 \%)$, Dois Irmãos do Buriti (99,25\%), Anastácio (98,87\%) e Aquidauana (97,53\%), respectivamente. 
Tabela 2 - População inserida na Bacia Hidrográfica do Rio Aquidauana

\begin{tabular}{lrrrr}
\hline Município & $\begin{array}{r}\text { População total } \\
\text { (em hab) }\end{array}$ & $\begin{array}{r}\text { População na } \\
\text { bacia (em hab) }\end{array}$ & $\begin{array}{r}\text { Porcentagem sobre } \\
\text { a população total do } \\
\text { município (em \%) }\end{array}$ & $\begin{array}{r}\text { Porcentagem sobre } \\
\text { a população total da } \\
\text { bacia (em \%) }\end{array}$ \\
\hline Anastácio & 23.835 & 23.566 & 98,87 & 18,82 \\
\hline Aquidauana & 45.614 & 44.491 & 97.53 & 35,54 \\
\hline Bandeirantes & 6.609 & 1.051 & 15,90 & 0,84 \\
\hline Camapuã & 13.625 & 2 & 0,01 & 0,00 \\
\hline Campo Grande & 786.797 & 1.400 & 0,17 & 1,12 \\
\hline Corguinho & 4.862 & 2.797 & 57,52 & 2,23 \\
\hline Dois Irmãos do Buriti & 10.363 & 10.286 & 99,25 & 8,22 \\
\hline Jaraguari & 6.341 & 4.340 & 68,44 & 3,47 \\
\hline Maracaju & 37.405 & 1.092 & 2,91 & 0,87 \\
\hline Miranda & 25.595 & 4.145 & 16,19 & 3,31 \\
\hline Nioaque & 14.391 & 3.496 & 24,29 & 2,79 \\
\hline Rio Negro & 5.036 & 13 & 0,25 & 0,01 \\
\hline Rochedo & 4.928 & 4.928 & 100,00 & 3,94 \\
\hline São Gabriel do Oeste & 22.203 & 210 & 0,94 & 0,17 \\
\hline Sidrolândia & 42.132 & 6.255 & 14,50 & 5,00 \\
\hline Terenos & 17.146 & 17.120 & 99,84 & 13,67 \\
\hline Total & $\mathbf{1 . 0 6 6 . 8 8 2}$ & $\mathbf{1 2 5 . 1 9 2}$ & - & 100,00 \\
\hline Fonal & & & \\
\hline
\end{tabular}

Fonte: ${ }^{1}$ IBGE (2010).

Mais uma vez, de acordo com os dados levantados, pode-se deduzir que os municípios mais representativos da bacia hidrográfica do rio Aquidauana são os de Aquidauana, Anastácio, Dois Irmãos do Buriti, Terenos e Rochedo, ou seja, cinco municípios dentre os dezesseis que estão inseridos na bacia.

Portanto, no que se refere à área e à população, esses cinco municípios são os mais representativos da bacia hidrográfica do rio Aquidauana.

\section{A BACIA HIDROGRÁFICA DO RIO AQUIDAUANA: USO E OCUPAÇÃO DO SOLO}

A ocupação do solo na bacia hidrográfica do rio Aquidauana apresenta diferentes formas de assentamentos humanos, tais como, assentamentos rurais, terras indígenas e distritos rurais (Tabela 3). Foram identificados 19 assentamentos rurais, sendo que quatro abrangem áreas territoriais de mais de um município (Assentamento Marcos Freire, entre os municípios de Anastácio e Dois Irmãos do Buriti, Assentamento Santa Guilhermina e Uirapuru, entre os municípios de Nioaque e Maracaju, Assentamento Bandeirante do Agachi, entre os municípios de Aquidauana e Miranda), 5 terras indígenas (algumas ampliadas e abrangendo mais de um município, considerando que as terras indígenas são compostas por várias aldeias) e 10 distritos rurais. 
Tabela 3 - Uso e Ocupação na Bacia Hidrográfica do Rio Aquidauana

\begin{tabular}{lccc}
\hline Municípios & Assentamento Rural & Terra Indígena $^{\mathbf{1}}$ & Distrito $^{\mathbf{2}}$ \\
\hline Anastácio & 4 & 0 & 0 \\
\hline Aquidauana & 1 & 3 & 3 \\
\hline Bandeirantes & 0 & 0 & 1 \\
\hline Camapuã & 0 & 0 & 0 \\
\hline Campo Grande & 1 & 0 & 1 \\
\hline Corguinho & 0 & 0 & 1 \\
\hline Dois Irmãos do Buriti & 2 & 1 & 1 \\
\hline Jaraguari & 1 & 0 & 1 \\
\hline Maracaju & 2 & 0 & 0 \\
\hline Miranda & 1 & 1 & 0 \\
\hline Nioaque & 5 & 0 & 0 \\
\hline Rio Negro & 0 & 0 & 0 \\
\hline Rochedo & 0 & 0 & 1 \\
\hline São Gabriel do Oeste & 0 & 0 & 0 \\
\hline Sidrolândia & 2 & 0 & 1 \\
\hline Terenos & 4 & 0 & $\mathbf{1 0}$ \\
\hline Total & $\mathbf{2 3}$ & $\mathbf{5}$ & \\
\hline Fonte: 'MASUL & & & \\
\hline
\end{tabular}

Fonte: ${ }^{1}$ IMASUL (2008); ${ }^{2}$ DNIT (2013).

Uma análise sobre a situação do saneamento básico na bacia hidrográfica do rio Aquidauana demonstra que duas cidades às suas margens captam água superficial do rio para o abastecimento humano, enquanto que as outras seis cidades captam água subterrânea para o abastecimento da população urbana (através de poços). De oito cidades inseridas na bacia, apenas duas não possuem nenhuma extensão de rede de coleta de esgoto, entretanto o tratamento do esgoto, mesmo que parcial, foi observado em apenas duas cidades (Quadro 1).

\begin{tabular}{|c|c|c|c|c|c|c|}
\hline Municípios & $\begin{array}{c}\text { Aterro } \\
\text { Sanitário }\end{array}$ & $\begin{array}{l}\text { Depósito a } \\
\text { céu aberto }\end{array}$ & $\begin{array}{l}\text { Captação de } \\
\text { água (água } \\
\text { subterrânea) }\end{array}$ & $\begin{array}{l}\text { Captação de } \\
\text { água (água } \\
\text { superficial) }\end{array}$ & $\begin{array}{c}\text { Coleta de } \\
\text { esgoto }\end{array}$ & $\begin{array}{l}\text { Tratamento } \\
\text { de esgoto }\end{array}$ \\
\hline Anastácio & Sim & Sim & Sim & Sim & Sim & Sim \\
\hline Aquidauana & Sim & Sim & Não & Sim & Sim & Sim \\
\hline Corguinho & Não & Sim & Sim & Não & Sim & Não \\
\hline Dois Irmãos & Sim & Não & Sim & Não & Não & Não \\
\hline Jaraguari & - & - & - & - & - & - \\
\hline Rochedo & Não & Sim & Sim & Não & Não & Não \\
\hline Sidrolândia & Não & Sim & Sim & Não & Sim & Não \\
\hline Terenos & Sim & Não & Sim & Não & Sim & Não \\
\hline
\end{tabular}

Quadro 1 - Situação do saneamento básico na bacia do rio Aquidauana Fonte: ${ }^{1}$ IMASUL (2008); ${ }^{2}$ DNIT (2013).

Quanto à infraestrutura viária, várias rodovias federais e estaduais possuem traçados no interior da bacia e algumas rodovias atravessam o rio Aquidauana, sendo que foram identificadas 11 pontes cruzando o rio Aquidauana (Tabela 4). 
Tabela 4-Pontes sobre o rio Aquidauana em rodovias federais e estaduais

\begin{tabular}{l|c}
\hline Localização (município) & Quantidade de Pontes \\
\hline Anastácio/Aquidauana & 4 \\
\hline Aquidauana/Terenos & 2 \\
\hline Corguinho/Rochedo & 4 \\
\hline Dois Irmãos do Buriti & 1 \\
\hline Total & $\mathbf{1 1}$ \\
\hline
\end{tabular}

Fonte: DNIT (2013).

Na Figura 4, são visualizados os elementos que compõem a organização espacial da bacia hidrográfica do rio Aquidauana, a saber: a estrutura viária e a ocupação do solo. A partir disso, pode ser feita uma análise da distribuição espacial desses elementos e da relação dessa distribuição com a situação do leito principal.

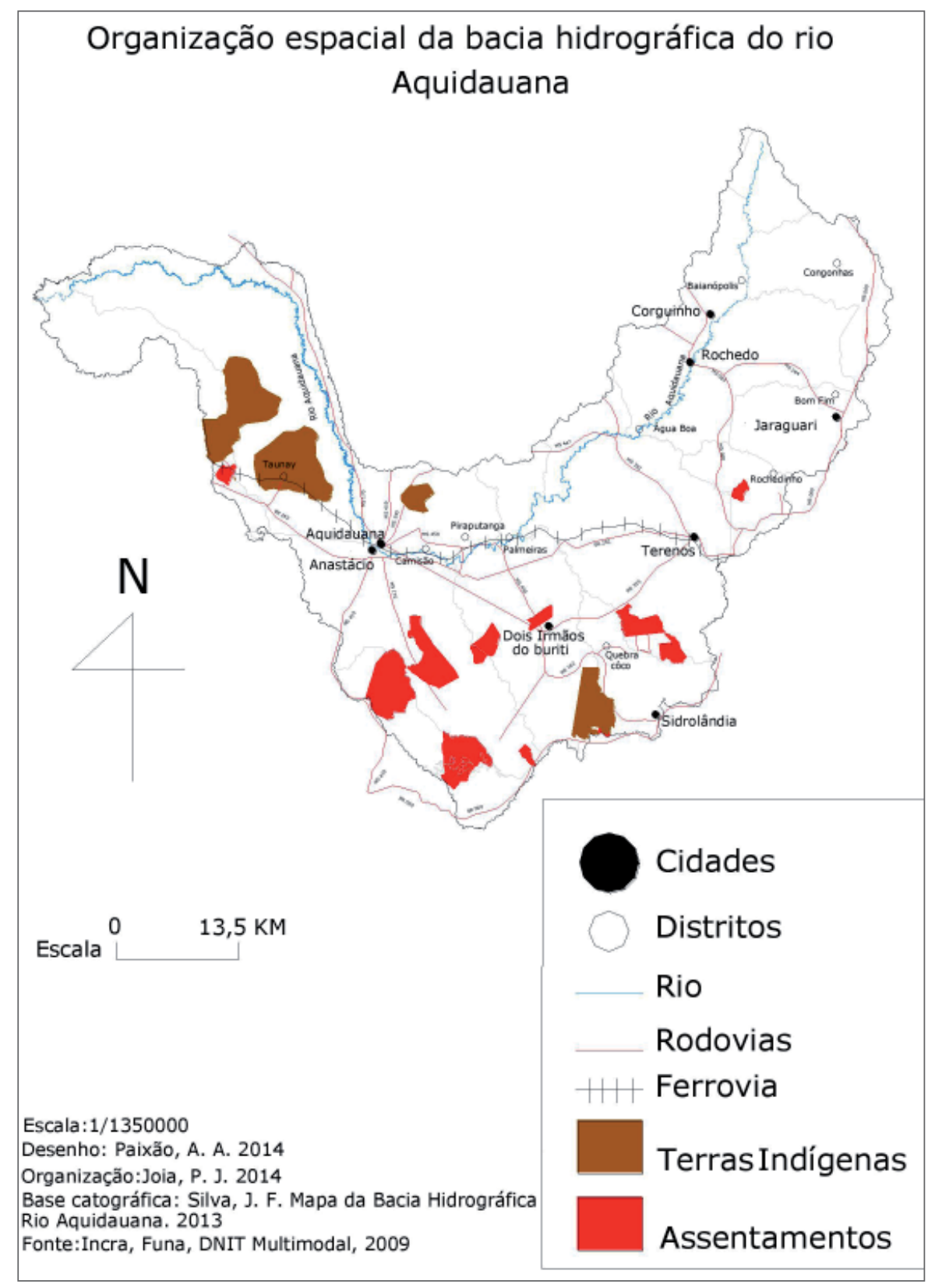

Figura 4 - Organização espacial da Bacia Hidrográfica do Rio Aquidauana Fonte: DNIT (2013). 
Verificou-se que as atividades econômicas ao longo do rio Aquidauana e no interior da bacia apresentam-se bastante dispersas e diversificadas. Não foram inseridas, no mapa de organização espacial da bacia hidrográfica do rio Aquidauana, as atividades industriais mais representativas, ligadas aos ramos da frigorificação e cerâmica, por serem localizações muito pontuais e de pouca expressividade, o que não provocaria transformações significativas na paisagem natural e na organização do espaço regional.

As áreas de predomínio de monoculturas de soja, de cana-de-açúcar e de eucalipto tiveram crescimento em área principalmente no médio e alto curso do rio Aquidauana, porém o destaque maior é para a expansão das pastagens plantadas em substituição às áreas de cobertura vegetal natural composta por Cerrados.

Os municípios que compõem a área da bacia vêm passando por um processo de transformação articulado com o momento histórico do modo de produção capitalista em nível mundial, que se reestrutura mediante uma nova divisão do trabalho e valorização do espaço local, sendo que, nesse contexto, redefine a produção e a função do espaço, consolidando-se numa região especializada no agronegócio, principalmente na produção de carne bovina, e na atividade turística, especialmente no ecoturismo.

As transformações na organização espacial, relacionadas a essas atividades, gradativamente vêm contribuindo para o avanço da vulnerabilidade ambiental na região, sendo que a maior repercussão socioespacial dos eventos naturais, sobretudo os decorrentes do extremo climático, processam-se nos espaços urbanos, gerando inundações periódicas, e, nos espaços rurais, provocando a erosão do solo.

As formas de ocupação do espaço apresentam uma forte relação com as diferentes inclinações do relevo na bacia do rio Aquidauana. O sentido da disposição e predomínio de altas declividades, a montante, e de baixas declividades, a jusante, torna o baixo e médio curso passível à vulnerabilidade dos eventos climáticos extremos, sobretudo nos processos de precipitação, infiltração e percolação, recaindo, principalmente, sobre as cidades de Anastácio e Aquidauana.

No alto curso da bacia, sobretudo na região das cabeceiras, expande-se a urbanização e a agricultura, representada pelas lavouras temporárias e pela pecuária de corte e de leite; nesse caso, os impactos afetam diretamente as fontes alimentadoras do canal principal, com implicações no médio e baixo curso.

\section{POLÍTICA DE RECURSOS HÍDRICOS: COMITÊS E CONSÓRCIOS ESTADUAIS}

A Política Nacional dos Recursos Hídricos (BRASIL, 1997), através do Sistema Nacional de Gerenciamento de Recursos Hídricos, instituída pela Lei Federal 9433, de 08 de janeiro de 1997 (Lei das Águas), sinalizou para a importância da organização de comitês de bacias hidrográficas em todo o Brasil. Esse Sistema é integrado pelo Conselho Nacional de Recursos Hídricos (CNRH), criado em 1998. No nível de planejamento das bacias hidrográficas, existem os Planos Estaduais que fundamentam a política nacional e o gerenciamento dos recursos hídricos. Os Comitês constituem canais de discussão e cooperação entre as esferas federal, estadual e municipal, valorizando as parcerias interinstitucionais.

A bacia do rio Aquidauana é atendida por dois importantes organismos de gestão: o Comitê da Bacia Hidrográfica do Rio Miranda (CBH Rio Miranda) e o Consórcio Intermunicipal para o Desenvolvimento das Bacias dos Rios Miranda e Apa (CIDEMA). 
O CIDEMA foi criado em 1998, sendo uma ação pioneira de prefeitos da região. O Consórcio é um órgão de importância política para o planejamento e a gestão da bacia do rio Aquidauana, que pertence à bacia do rio Miranda. O CIDEMA tem por objetivo gerar o desenvolvimento integrado regional na área de atuação do órgão.

Inicialmente, faziam parte do Consórcio 14 municípios do estado de Mato Grosso do Sul, dos 26 municípios pertencentes à bacia dos rios Miranda e Apa, entre eles: Anastácio, Antonio João, Bela Vista, Bonito, Bodoquena, Caracol, Camapuã, Corguinho, Guia Lopes da Laguna, Jardim, Miranda, Maracaju, Nioaque e Porto Murtinho.

Em 2011, o CIDEMA passa ao nível de Consórcio Público, regido pela Lei Federal n. 11.107, de 6 de abril de 2005, que estabelece, em seu Artigo 1ำ, que os municípios podem contratar consórcios públicos para a realização de objetivos de interesse comum em diversas áreas, mediante a subscrição de protocolo de intenções, não havendo a necessidade de o município consorciado integrar a bacia para se tornar um município participante (BRASIL, 2005).

Atualmente, 24 municípios fazem parte do consórcio, sendo que 11 municípios solicitaram adesão ao consórcio, sendo eles: Jaraguari, Ladário, Aquidauana, Dois Irmãos do Buriti, Bandeirantes, Rio Brilhante, Corumbá, Rio Negro, Rochedo, Sidrolândia e Terenos, e um município solicitou a saída do consórcio: o de Bodoquena.

Segundo o Secretário-geral do CIDEMA (ANASTÁCIO, 2011), o órgão tem por objetivo estabelecer relações entre o desenvolvimento regional, a preservação ambiental e o saneamento básico dos municípios que integram a bacia hidrográfica dos rios Miranda e Apa. O CIDEMA colabora com as prefeituras municipais na execução de planos, programas, projetos e medidas conjuntas, fornecendo cooperação técnica e encaminhamento para as fontes de recursos financeiros, que visam ao desenvolvimento sustentável, promovendo a melhoria das condições de vida da população.

O Comitê de Bacia Hidrográfica do Rio Miranda foi criado, em 25 de outubro de 2005, pelo Conselho Estadual de Recursos Hídricos, através de uma parceria entre o Fundo Mundial para a Natureza (WWF-Brasil), o CIDEMA e a Secretaria Estadual de Meio Ambiente (SEMA). O Comitê tem funções deliberativas e as ações serão executadas pela Agência de Água, mediante autorização do Conselho Estadual de Recursos Hídricos.

Os 23 municípios membros do Comitê são: Anastácio, Aquidauana, Bandeirantes, Boa Vista, Bodoquena, Bonito, Corguinho, Campo Grande, Corumbá, Dois Irmãos do Buriti, Guia Lopes da Laguna, Jaraguari, Jardim, Maracaju, Miranda, Nioaque, Ponta Porã, Porto Murtinho, Rochedo, Rio Negro, São Gabriel do Oeste, Sidrolândia e Terenos.

O CBH Rio Miranda é composto administrativamente por 33 membros divididos em 11 membros representantes do poder público (cinco secretarias estaduais, quatro prefeituras indicadas das 23 da bacia, FUNAI e IBAMA), 11 representantes dos usuários de água e 11 representantes das organizações de sociedade civil.

De acordo com o regimento interno, o Comitê organiza o cadastramento das organizações civis de recursos hídricos, dos representantes de usuários e dos representantes dos municípios para a sua composição.

O Comitê é responsável pela gestão dos recursos hídricos de toda a região que abrange a bacia do rio Miranda, inclusive a bacia do rio Aquidauana. Os comitês são responsáveis por decidir conflitos de uso da água, se haverá cobrança ou não sobre o uso dos recursos hídricos e toda a gestão da bacia. 
Verificou-se que tanto o Comitê quanto o Consórcio precisam de uma recomposição e renovação do quadro de representantes para adquirir uma postura mais atuante em diversas situações em que se envolve o recurso hídrico tanto em questões econômicas ligadas ao abastecimento urbano e usos industriais quanto em questões ambientais. Porém, este tipo de organização social não pode ser transformado em bandeira política para interesses específicos da bancada ruralista na Assembleia Legislativa Estadual e no Congresso Nacional, o que descaracterizaria seus objetivos básicos.

\section{CONCLUSÕES}

A partir das análises dos dados levantados, verificou-se que a bacia do rio Aquidauana possui uma baixa densidade demográfica, de que se deduz que as atividades socioeconômicas exercem pouca pressão sobre os recursos existentes.

A pesquisa identificou que os municípios mais representativos em área e população na bacia hidrográfica do rio Aquidauana são os de Aquidauana, Anastácio, Dois Irmãos do Buriti, Rochedo e Terenos. Constatou-se que esses municípios fazem parte dos órgãos de gestão da bacia, o que poderá facilitar as ações de planejamento e gestão e contribuir para a sustentabilidade da bacia.

Verificou-se que as sedes municipais mais afetadas por inundações periódicas, localizam-se no médio-baixo curso do rio Aquidauana, sendo que estas sofrem com todas as transformações antrópicas sobre o meio natural ocorridas no médio e alto curso da bacia.

Com relação à infraestrutura viária existente na bacia hidrográfica do rio Aquidauana, percebe-se que a quantidade de rodovias (11 estaduais e duas federais) e uma ferrovia possibilitam o acesso aos pontos de interesse econômicos e sociais destacados. Com relação aos assentamentos humanos, foram destacados os assentamentos rurais, terras indígenas e distritos, estes sendo pontos de aglomeração populacional importantes, depois das sedes municipais, para o uso dos recursos hídricos da bacia.

Com relação ao saneamento básico na bacia hidrográfica do rio Aquidauana, verificou-se que quatro cidades localizam-se às margens do rio Aquidauana, implicando baixa retirada de recursos hídricos para o consumo humano. Por outro lado, o sistema de coleta e tratamento do esgoto está parcialmente implantado nessas cidades, o que traz sérias implicações para a qualidade da água do rio. Quanto ao sistema de coleta e deposição final do lixo, este é feito em sua maioria por meio de depósito a céu aberto. Em síntese, a situação do saneamento básico merece maior atenção do poder público e dos órgãos de gestão da bacia.

Em relação ao planejamento e gestão da bacia hidrográfica do rio Aquidauana, há uma necessidade de aplicação Zoneamento Ecológico Econômico para disciplinar o uso e a ocupação do solo e disciplinar o multiuso da água da bacia para o turismo de pesca e lazer, para a manutenção de comunidades ribeirinhas e para o abastecimento humano e necessidades do saneamento básico.

Portanto reivindica-se o cumprimento da Política Nacional de Recursos Hídricos e a composição diversificada dos Consórcios e Comitês existentes para o desenvolvimento sustentável e integrado do território da bacia hidrográfica do rio Aquidauana. Essas alterações na política institucional dos órgãos ligados à bacia são necessárias para que não se privilegie apenas a expansão do agronegócio ligado à carne, aos grãos e à madeira, com o propósito de geração de emprego, e deixe, para segundo plano, a sustentabilidade da sociodiversidade, composta por 
ribeirinhos e indígenas entre outras comunidades locais dependentes do recurso hídrico, e da biodiversidade do binômio Cerrado e Pantanal.

\section{REFERÊNCIAS}

ANASTÁCIO (Município). Douglas Figueiredo ministra palestra sobre o CIDEMA em capacitação estadual da FETAGRI. Portal da Prefeitura Municipal. Prefeitura Notícias, 20 de julho de 2011. Disponível em: <www.anastacio.ms.gov.br/noticia-848-douglas-figueiredo-ministra-palest>. Acesso em: 19 maio 2014.

BORSOI, Z. M. F.; TORRES, S. D. A. A política de recursos hídricos no Brasil. Revista do BNDES, Rio de Janeiro, n. 806, p. 1-15, 1997.

BRASIL. Presidência da República. Lei n. 11.107, de 6 de abril de 2005. Dispõe sobre normas gerais de contratação de consórcios públicos e dá outras providências. Disponível em <http://www.planalto.gov. br/ccivil_03/_ato2004-2006/2005/lei/l11107.htm>. Acesso em: 10 maio 2014.

. Presidência da República. Lei n. 9433, de 8 de janeiro de 1997. Institui a Política Nacional de Recursos Hídricos. Disponível em: <http://www.planalto.gov.br/ccivil_03/leis/L9433.htm>. Acesso em: 10 maio 2014.

BROCH, Synara. A. O. Mato Grosso do Sul - a fronteira é hídrica. Revista Águas do Brasil, Edição 6, 2013. Disponível em: <http://aguasdobrasil.org/edição-06/mato-grosso-do-sul-a-fronteira-e-hidrica.html>. Acesso em: 5 abr. 2014.

CHRISTOFOLETTI, Antonio. Geomorfologia. 2. ed. São Paulo: Edgard Blücher, 1980.

COMITÊS DE BACIAS HIDROGRÁFICAS (CBH). Disponível em: <http://www.cbh.gov.br/GestaoComites. aspx>. Acesso em: 13 abr. 2014.

CONSELHO NACIONAL DE RECURSOS HÍDRICOS (CNRH). O Conselho CNRH. [s.d.]. Disponível em: <http:// www.cnrh.gov.br/index.php?option=com_content\&view=article\&id=1>. Acesso em: 13 abr. 2014.

DEPARTAMENTO NACIONAL DE INFRA-ESTRUTURA DE TRANSPORTES (DNIT). Diretoria de Planejamento e Pesquisa. Mapa multimodal Mato Grosso do Sul 2013. Rede do PNV- Divisão em Trechos 2011. Brasília: Ministério dos Transportes, 2013. Disponível em: <http://www.dnit.gov.br/mapas-multimodais/mapasmultimodais/mapas-multimodais/mapas-multimodais/ms.pdf>. Acesso em: 15 mar. 2014.

INSTITUTO BRASILEIRO DE GEOGRAFIA E ESTATÍSTICA (IBGE). Censo Demográfico de 2010. Sinopse por Setor. Disponível em <http://www.censo2010.ibge.gov.br/sinopseporsetores/?nivel=st>. Acesso em: 15 mar. 2014.

INSTITUTO DE MEIO AMBIENTE DE MATO GROSSO DO SUL (IMASUL). Dados complementares: PA INCRA 2005 e Terras Indígenas MS FUNAI 2008. Disponível em: <http://sisla.imasul.ms.gov.br/sisla/aplicmap/ sisla.htm>. Acesso em: 17 jul. 2014.

MARINHO, V. L. F.; MORETTI, E. C. A apropriação e domínio da água na sociedade contemporânea: políticas públicas de recursos hídricos e a criação dos comitês de bacia hidrográficas no Mato Grosso do Sul. In: ENSUL, 21., e EREGEO, 5. Dourados, MS, 26 a 28 de junho de 2013.

MATO GROSSO DO SUL. Secretaria de Estado de Meio Ambiente, do Planejamento, da Ciência e Tecnologia. Instituto de Meio Ambiente de Mato Grosso do Sul. Plano estadual de recursos hídricos de Mato Grosso do Sul. Campo Grande, MS: Editora UEMS, 2010. 194p.

MENDONÇA, Francisco. Diagnóstico e análise ambiental de microbacia hidrográfica: proposição metodológica na perspectiva do zoneamento, planejamento e gestão ambiental. RA'E GA. O espaço geográfico em análise, Curitiba, n. 3, p. 67-89, 1999.

PORTO, M. F. A.; PORTO, R. L. Gestão de bacias hidrográficas. Estudos Avançados, São Paulo, v. 22, n. 63, p. $43-$ 60, 2008. Disponível em: <http://www.scielo.br/scielo.php?pid=S0103-40142008000200004\&script=sci_ arttext\&tlng=es>. Acesso em: 29 ago. 2013. 
SECRETARIA DE ESTADO DE MEIO AMBIENTE, DO PLANEJAMENTO E DA CIÊNCIA E TECNOLOGIA (SEMAC)/ INSTITUTO DE MEIO AMBIENTE DE MATO GROSSO DO SUL (IMASUL). Diagnóstico da bacia hidrográfica do rio Miranda. Campo Grande, MS, 2013.

SECRETARIA DE ESTADO DE MEIO AMBIENTE, DO PLANEJAMENTO E DA CIÊNCIA E TECNOLOGIA (SEMACMS). Caderno Geoambiental das Regiões de Planejamento de MS. Campo Grande, 2011.

SECRETARIA DE PLANEJAMENTO E COORDENAÇÃO GERAL (SEPLAN-MS). Atlas Multirreferencial do Estado de Mato Grosso do Sul. Campo Grande, MS: SEPLAN/IBGE, 1990.

SILVA, J. F. Mapa da bacia hidrográfica do rio Aquidauana. Projeto Análise ambiental integrada da bacia hidrográfica do rio Aquidauana: uma contribuição ao ordenamento físico-territorial, planejamento e gestão do espaço. Aquidauana, MS: UFMS, 2013.

TUNDISI, J. G. Recursos hídricos no futuro: problemas e soluções. Estudos Avançados, São Paulo, v. 22, n. 63, p. 7-16, 2008. Disponível em: <http://www.scielo.br/pdf/ea/v22n63/v22n63a02.pdf>. Acesso em: 26 ago. 2013.

YASSUDA, E. R. Gestão de recursos hídricos: fundamentos e aspectos institucionais. Revista de Administração Pública, Rio de Janeiro, v. 27, n. 2, p. 5-18, abr./jun. 1993. Disponível em: <http://bibliotecadigital.fgv.br/ ojs/index.php/rap/article/view/8663/7394>. Acesso em: 29 ago. 2013.

\section{Sobre os autores:}

Paulo Roberto Joia: Doutor em Geografia. Professor do curso de Geografia e do Programa de Mestrado em Geografia do Campus de Aquidauana da UFMS.E-mail: paulo.joia@ufms.br

Vicentina Socorro da Anunciação: Doutora em Geografia. Professora do Curso de Geografia e do Programa de Mestrado em Geografia do Campus de Aquidauana da UFMS. E-mail: viqueceua@bol.com.br

Alfredo Aguirre da Paixão: Mestrando em Geografia do Campus de Aquidauana da UFMS. E-mail: alfredoadp@hotmail.com 